\title{
INTRODUCTION TO HOW TO DO RELEVANT RESEARCH
}

There has never been a more important time for researchers to generate useful knowledge, catalyze change, and contribute to managerial and organizational effectiveness. To adapt to upheavals in the economic, technical, ecological, social, and political landscape, managers need practical insights, research-based evidence, and knowledge partners to inform and guide their actions. Will organizational researchers be there to help them in this transition? Can we journey from the ivory tower to confront the real world challenges faced by organizations and their stakeholders?

Questions about relevance have been the subject of debate for decades in academe where research to develop and test theory has been emphasized over research that supports practice. ${ }^{1}$ This book makes a case that systematic research can be informed by and contribute to theory and, at the same time, produce knowledge relevant to the problems faced in practice. There is a sweet spot where you can do both scholarly and practical research and we're going to show you how to get there.

Our aim is to speak to the "graduate student in all of us" - as an introduction to $\mathrm{PhD}$ students and early career academics who gravitate to this kind of research but worry about its feasibility and instrumentality; a refresher to mid-to-late career scholars who do research for practice and teach young scholars how to do it; and a resource to researchers in a think-tank, institute, or consultancy who want their work to be scientifically sound and practically useful.

\section{THE CASE FOR RELEVANT SCHOLARSHIP}

Doing relevant research means studying the real issues, problems, and demands facing organizations and the people that work in and manage them. It means generating knowledge that is (1) applicable to practice; (2) useful to practitioners; and (3) actionable. And to this we add a fourth condition - that your research be grounded in theory, your methods hew to standards of reliability and validity, and your findings speak to the literature and your academic peers as well as to practitioners. It is this middle space between the worlds of academe and practice that we put ourselves as researchers, and encourage you to consider. As you will see, operating in this "sweet spot" is, as a wise professor put it, "wonderfully complex, not easy, and presents a new puzzle every few steps." It also poses choices and tradeoffs for you as a researcher.

This was the kind of research for theory and practice done by our mentors and professors, who learned from their close connection to practice, and who urged us to do the same. You will hear from some of them-Edward Lawler, Michael Porter, Denise Rousseau, Edgar Scheinand learn about their motivations, strategies, and challenges in doing this kind of research. But they, and we, entered academe in a different time and things have changed. Nowadays, these scholars and their contributions continue to be admired and cited, but too few professors strive to emulate them.

In the world of organizational scholarship today, there is rising angst about the irrelevance of management research and teaching, and growing debate about the spread of the "American" 
model of scholarship to business and management schools around the world. ${ }^{3}$ The central concerns are that business schools have defined themselves as theory- and research-based institutions and that faculty publications in theory-oriented, peer-refereed, top-tier journals have become, as former president of the Academy of Management Tom Cummings observed, the "gold standard and primary determinant of a business school's prestige." Consequently, academic theorizing about organizations and their management has become more distant from practice; research rigor has been emphasized over relevance.

This is not simply a philosophical choice for a business school and its faculty members-it has implications for a school's ranking and reputation, student and faculty recruiting (and retention), and accreditation. The AACSB (the America-based Association to Advance Collegiate Schools of Business, whose reach extends globally) and its European counterpart the EFMD (European Foundation for Management Development) put a premium on discipline-based research as opposed to scholarship aimed at practice or management education. It has reached the point that many business school professors spend little time interacting with practitioners and companies, and their schools must employ non-tenured clinical faculty and consultants as adjuncts to teach practically minded MBAs and provide executive education.

A range of studies suggest that practitioners struggle to find academic studies of potential relevance to them and, when they do, have a difficult time understanding academic argument and jargon let alone discovering anything practical they can use. ${ }^{4}$ Whether this reflects (1) a knowledge production problem or (2) a knowledge translation problem is an open question. ${ }^{5}$ Are researchers today guided by theories and methodologies divorced from organizational perspectives and realities? If so, their research has little relevance and applicability to practitioners. Or, do researchers fail to translate and disseminate effectively the knowledge they generate so that practitioners can understand and apply it? In our view: both problems hinder us from doing relevant research.

Responding to calls for more practice impact requires a self-examination of our fields of inquiry and the theories and methodologies we employ, the problems we examine, and the way our work connects to the organizations that are shaping our future. We need to reconsider whether our dominant, hands-off, and theory-oriented approach to research has left us in the roles of chroniclers, explainers, and tacit enablers of the status quo rather than generators of knowledge that helps to shape how organizing can unfold differently and more effectively.

We believe researchers can get beyond the insulated and singular motivation of advancing disciplinary knowledge and can commit to scholarship that is responsive to the complexity of practitioner challenges. To do so we have to be close enough to organizational realities to see how they are changing, to understand how they relate to our theoretical concepts, and to appreciate their impacts on outcomes of interest to economies, humanity, and the earth. This is particularly important during periods of upheaval and transformation-like now! When practitioners experience new problems, they need to step outside a daily reality defined by their implicit theories and existing solutions. As researchers, we can and should be there with innovative, thought-provoking frameworks and credible findings. 


\section{REPURPOSING MANAGEMENT AND ORGANIZATION RESEARCH}

The origins of this book trace to the dawn of the new millennium when Mohrman called on researchers to "Seize the Day":

This is a time in history when organizational studies can and should contribute to the shaping of organizations and institutions that have immense impact on the character and quality of life. The unfolding global knowledge economy has presented great turbulence and contradiction: entailing unparalleled opportunity and largesse for some, decreased fortune for others, and the challenge of adapting to a new order for all but the most recent entrants to the workforce. ${ }^{6}$

Since then we have witnessed global terrorism and the downing of the Twin Towers in New York City; the dot.com bust of 2000 and financial crisis of 2008; ever dire warnings on the impact of climate change; the Arab Spring, Brexit, and social movements ranging from Occupy Wall Street to \#MeToo to Black Lives Matter; the COVID-19 pandemic; political unrest in the US and elsewhere; and growing attention to sustainability and social issues by business. Digital companies like Amazon, Facebook, and Google, alongside Apple, now dominate the Fortune 100 while new organization forms have emerged involving peer-to-peer sharing and gig workers or combining social and economic objectives in "hybrid" business models and B Corps. New strategic challenges stem from geopolitical uncertainty and realignment as dominant Western economies and cultures are being challenged by strengthening economies and different socio-political and cultural frameworks in the global East and South.

In a matter of decades, fundamental disruptions associated with globalization and digitalization have propelled significant changes in organizational operations and raised fundamental questions about business purposes and responsibilities. These disruptive changes have created many new areas for scholarly investigation and challenged the continuing relevance of knowledge developed in earlier stages of industrial organization. Our existing understandings of employee commitment may not fit in today's work world. People are globally dispersed, culturally diverse, and mobile, and companies no longer offer a secure employment relationship or even employment status to those who deliver on the organization's mission. Our current work designs and mechanisms of control, coordination, and accountability seem ill-adapted to the movement toward robotics and smart IT platforms that carry out decision-making and learn. Ask yourself: Do prevailing assumptions about the objective function of wealth creation make sense when current practices have detracted from human dignity and wellbeing, equity, and the health of the natural ecology? Our organization theories and research studies will have to change to embed these other valued outcomes.

Meanwhile, new ideas have been introduced that enrich theorizing and our research methods. Complexity theory, neuroscience, artificial intelligence, evolutionary biology, and behavioral economics infuse important new perspectives into the study of social systems. Theorizing, at least among post-modernists, has taken a "linguistic turn". Researchers of this stripe "read" organizational speech and doings and deconstruct them by, among other 
methods, looking for alternative interpretations, exploring what is not being said or done, flipping things around to see the "other side" of the story, and seeking out the voices of the underrepresented or marginalized. Theorizing has also taken a "practice turn" (e.g., strategy-as-practice). These approaches and others, including critical management theory, positive organization scholarship, and organizational aesthetics, give us new "lenses" to see what is going on in organizations. Research findings generated from these diverse angles can variously wake up practitioners to troubling realities, affirm positive trajectories, or afford them a fresh perspective on what they are doing.

\section{GETTING KNOWLEDGE TO PRACTICE}

When we took our first academic posts, the main highway between research and practice went through classroom teaching and executive education, textbook writing, publications in practitioner-oriented journals, and professional books. This knowledge value stream is still in place but just as industries and ecosystems evolve, so too has the value stream through which organizational knowledge is generated and communicated to practitioners.

Universities, for example, have established multi-disciplinary and multi-stakeholder research centers. Scholars from different backgrounds develop and exchange knowledge with one another and with practitioners in health care, technology, nonprofit and government services, and arts/entertainment or with functional specialists in HR, IT, marketing, and engineering. Researcher and practitioner communities have formed to study organization learning, diversity and inclusion, commercial and social innovation, organization design, sustainability, and developments in technology and social media. Private research centers, foundations, and professional service/consulting firms are also in the business of generating and getting knowledge into practice.

All this raises some practical questions for you: How will you keep abreast of and engage with the world of practice in framing and doing your research? Do you want to do research solely within the confines of your academic department and discipline or connect to and even collaborate with different sorts of researchers, perhaps in alternative research venues? Can you imagine collaborating with managers and organizations or joining in a knowledge network to do your research?

Knowledge is now being transmitted to practice in new forms. Blogs, podcasts, and YouTube videos convey "bite-size" bits of knowledge in short, digestible, and entertaining formats. PowerPoint presentations, storyboards, and infographics that explain research and its findings can be downloaded in an instant. Diagnostic surveys, action frameworks, and tools like decision trees or the business-model canvas help practitioners apply research-based knowledge or do research in their own organizations. Now you may sniff that these kinds of knowledge "products" distort the nuances and simplify the complexities of your research. They can ... and that's why those academics who want to speak to theory and practice use different channels to reach these two different audiences-and with appropriately tailored products.

This book is about doing and communicating relevant organizational research in this new environment. It is informed by our experiences and the counsel of scholars whom we 
interviewed to enrich, refine, and reality-test our points of view. We do not intend this as a full-throated critique of scholarly dysfunctions in the business school. Indeed, academic researchers have produced rich theoretical frameworks on motivation, leadership, innovation, open and socio-technical systems models of organization, structure-conduct-performance relationships and contingencies, and theorizing on networks, competing values, strategic capabilities, and evolutionary change that have informed both scholarship and practice.

Many organizational researchers, including those we interviewed in developing this book, advance theoretical perspectives even as they study subjects vital to organizational functioning and human welfare. This means doing more than just a one-off translation of an empirical article for the Harvard Business Review (HBR) to demonstrate relevance. They have embraced a research process that contributes to both theory and practice-and informs both scholars and doers. You will read in the volume about how they produce theoretically grounded knowledge to improve practice in such areas as adapting to digitalization and globalization, increasing organization agility and ambidexterity, fostering responsible leadership and stakeholder management, developing sustainability and social responsibility, and promoting diversity, inclusion, equity, and social justice at work along with work-life integration.

\section{IS THIS BOOK FOR YOU?}

In talking with our colleagues, we've shared a lot of head shaking over how theory and research are increasingly disconnected from practice. In academic circles today, practice-minded researchers are largely discounted and devalued. In conversations with doctoral students and junior faculty, we also hear and see a lot of "pain". It is expressed in cynicism about the workings of academe, disillusionment that scholarship should make a difference in organizations and society, and disappointment in themselves for giving up animating ideals and following along mainstream norms.

We believe, and will provide examples that show, that it is possible to shape your research career so that it generates knowledge that influences practice. Our aim is to get you thinking deeply about these matters. We provide frameworks, exemplars, ideas, and tools to guide you in the life-long tasks of defining yourself as a researcher and crafting your research practice. And we invite you to travel beyond the seemingly safe pathways laid out for you in your training, and develop a research career where you step into the middle ground where systematic research is connected to emerging organizational futures. The journey toward relevant research is yours.

- Are you a doctoral student or early-career professor who came to this field in hopes of doing something different from generating knowledge for its own sake? Do you aspire to develop and transmit knowledge to students and to practitioners for use in their careers or do research with practitioners and their organizations to help solve their problems? Are you being pushed to play the "A" journal publication game and counseled to "Wait 'til you get tenure, then you can worry about practice and 'saving the world'?" Or,

- Are you a scholar-practitioner employed in a management post or consulting firm who gravitated to doctoral scholarship to enhance your knowledge and advance pro- 
fessionally? Have you learned that you are an "outsider" whose practice knowledge is pooh-poohed in academic theorizing and whose motivations to apply knowledge to practice are vaguely suspect? As you take on the academic jargon and neologisms of organization science, do your work colleagues have any idea what you are talking about? Or,

- Are you a peripatetic professor who contributes to theory but also and especially wants to influence practice? Are you regularly reminded that $H B R$ is not an "appropriate" journal for academics? Worse, if you are graying, have you received unsubtle hints that you are holding on to a tenured slot that might better be filled by junior faculty socialized into a more "academic" approach to scholarship? Or,

- Are you doing your research outside of the university, in a research center, think-tank, or consultancy? Are you keeping track of relevant academic scholarship and wanting to collaborate with academics and practitioners to do relevant research?

If so, take heart, this book aims at you. It reimagines how to conduct management and organization research with the twin objectives of developing theory and impacting practice. For us, doing sound research that has practical relevance is a high calling and an adventure. To test and ultimately affirm that it has a place today in business school scholarship, we interviewed a number of our colleagues-and yours. ${ }^{7}$ Here you will find observations and reflections on doing this work from Max Bazerman, Mike Beer, John Boudreau, Wayne Cascio, Rob Cross, Amy Edmondson, Cristina Gibson, Adam Grant, Stu Hart, Mary Jo Hatch, Ed Lawler, Michael Porter, Bob Quinn, Denise Rousseau, Ed Schein, Majken Schultz, Bob Sutton, and Sandra Waddock, and from scholar practitioners like Sheila Bonini. Thanks to them and welcome to you.

\section{WHAT'S INSIDE?}

This volume is in two parts. Part I puts research for practice in its context and lays out the foundational bases of practical scholarship. The first chapter introduces you to what we call sweet spot research, what makes its knowledge relevant and useful, and how it connects to a broader ecosystem of knowledge generation and communication about organizations and their management. Chapter 2 asks you to reflect on the philosophical underpinnings of different research paradigms you might use and how you position yourself on a continuum of progressively engaged scholarship. Chapter 3 explores knowledge value streams to help you imagine ways to connect with other scholars, practitioners, and communities of practice to frame, do, and disseminate your research. In transitioning to Part II, Chapter 4 looks at historic exemplars of practical organization scholarship and how contemporary ones stand on their shoulders.

Part II concerns "how to" do research for practice with chapters on practical theorizing (Chapter 5), multiple research methods (Chapter 6), communicating to two different audiences (Chapter 7), and managing research relationships (Chapter 8). Note that this is not a research methods book. We assume here that you are familiar with the ins-and-outs of critically reading the literature, framing a problem statement, and formulating a research 
design. And we expect that you are conversant with different data gathering tools and matters of reliability, validity, and analytic techniques. What we present is not typically covered in your methods courses: How to do all of this with practice in mind and how to engage practitioners in your research.

A concluding Chapter 9 has you reflect on your professional identity in producing knowledge for theory and practice. Please note that throughout we have kept our references light primarily to acknowledge the main sources we draw from but not to cover the full canon of knowledge on subjects we address. Apologies and hats-off to so many authors whom we would surely cite in a more complete review of pertinent literature.

Preview over. Let's move into three different realms of management research: theory-driven, practice-driven, and the sweet spot.

\section{NOTES}

1. Kieser, A., Nicolai, A. and Seidl, D. (2015). The practical relevance of management research: Turning the debate on relevance into a rigorous scientific research program. Academy of Management Annals, 9(1), $143-233$.

2. Shay, J.P. (2008). A tale of a peripatetic professor: An interview with Craig C. Lundberg. Journal of Management Inquiry, 17(4), 341-52.

3. See Pfeffer, J. and Fong, C.T. (2002). The end of business schools? Less success than meets the eye. Academy of Management Learning \& Education, 1(1), 78-95; Mintzberg, H. (2004). Managers, not MBAs: A Hard Look at the Soft Practice of Managing and Management Development. Berrett-Koehler; Bennis, W.G. and O’Toole, J. (2005). How business schools have lost their way. Harvard Business Review, 83(5), 96-104; and Khurana, R. (2010). From Higher Aims to Hired Hands: The Social Transformation of American Business Schools and the Unfulfilled Promise of Management as a Profession. Princeton, NJ: Princeton University Press.

4. Rynes, S.L., Bartunek, J.M. and Daft, R.L. (2001). Across the great divide: Knowledge creation and transfer between practitioners and academics. Academy of Management Journal, 44(2), 340-55.

5. Shapiro, D.L., Kirkman, B.L. and Courtney, H.G. (2007). Perceived causes and solutions of the translation problem in management research. Academy of Management Journal, 50(2), 249-66.

6. Mohrman, S.A. (2001). Seize the day: Organizational studies can and should make a difference. Human Relations, 54(1), 57-65.

7. Interviewees were chosen based on their demonstrated ability to do research that is rigorous and relevant. This a convenience sample representing researchers whom we know based at different institutions. We questioned them about their research careers, professional identities and sense of purpose, how they theorized and did research, and the challenges encountered in doing relevant research and what helped them along the way. The interview material was sorted into conceptual groupings but not coded or subject to quantified analysis. 
Philip H. Mirvis, Susan Albers Mohrman, and Christopher G. Wor ley - 9781788119405 